Peter Binfield, Carly Strasser, and Nicole Allen

\title{
Updates from the field \\ Three experts provide a scholarly communication progress report
}

$\mathbf{F}_{\text {o }}^{\circ}$ or this month's column, the editors are taking the occasion of Open Access Week to look back at the achievements of the scholarly community in the past year. We have interviewed experts on open access (OA), open data and data management, and open educational resources. We asked each person the same five questions, and, taken together, the answers provide a snapshot of the current landscape around key issues in scholarly communication and a benchmark for coordinating future efforts.

\section{Interview with Peter Binfield on open access}

1. Please tell readers about yourself. Since graduating with a PhD in Underwater Holography, I have been a career publisher for 20 years, publishing books, reference works, subscription journals, and now OA journals. I joined the OA world in 2008 to run PLOS ONE, and I am convinced that OA is currently the best and most viable way to publish and distribute academic content for the overall betterment of society.

2. What do you think was the most significant development(s) in the landscape of $\mathrm{OA}$ in the past 12 months? At the moment, the best estimate is that by 2017 or 2018 , approximately $50 \%$ of all journal articles in that year will be published as "born open access." I believe that in the last 12 months there has been a sudden internalization of this fact by the wider publishing industry-namely that $\mathrm{OA}$ is about to become the dominant publication mode for journal articles. After a decade or more of attempting to ignore or fight this fact, many important players across the industry are now rapidly acting to address the new reality. As a result, we are seeing an explosion in OA options from established players, which can only be a good thing and which will ultimately benefit science and accelerate the dissemination of knowledge. It has been very encouraging to see this much movement in the last year.

\section{What issue(s) about OA do you think} warrants immediate attention and action? So-called "predatory journals" are a serious threat to the perception of the OA model. Deeply flawed studies such as the Bohannon sting (which simply showed that predatory publishers exist) are used to tar the whole of the OA world with the same negative brush. ${ }^{2}$ In my view, these scammers, and the people who are eager to promote their existence as an argument against $\mathrm{OA}$, are doing the credibility of the OA movement serious harm.

Peter Binfield is publisher and cofounder of PeerJ, email: pete@peerj.com, Carly Strasser is data curation specialist at California Digital Library, email: carly. strasser@ucop.edu, and Nicole Allen is director of open education SPARC, The Scholarly Publishing \& Academic Resources Coalition, email: nicole@sparc.arl.org

Contact series editors Zach Coble, digital scholarship specialist at New York University, and Adrian Ho, director of digital scholarship at the University of Kentucky Libraries, atcrlnscholcomm@gmail.com with article ideas

(C) 2014 Peter Binfield, Carly Strasser, and Nicole Allen, published under Creative Commons CC-BY 4.0 license, https://creativecommons.org/ licenses/by/4.0/ 
The industry needs to come to grips with this problem and deal with it in a prompt, effective, professional way.

4. What is your prediction of the development of $\mathrm{OA}$ in the next 12 months?

In the course of the next 12 months, pretty much every major publisher will have finished putting in place its own OA program, its own PLOS ONE clone(s), its own OA marketing efforts. As a result, academia will be bombarded with the message that $\mathrm{OA}$ is moving fast and that change is inevitable. At the same time, some of the biggest governmental OA mandates will start to have a real effect, e.g., the Fair Access to Science and Technology Act and the Research Councils U.K. policy in the United Kingdom. ${ }^{3}$ This will spur other governments and funders to implement strong mandates. Both of these developments will have a positive feedback effect that will further accelerate the movement towards full OA.

Authors (who are now being asked to pay for the service of an OA publication) will increasingly act as informed consumers and start to demand value for money. Already we are seeing the start of this movement with the recent protest letter over the pricing structure of the American Association for the Advancement of Science journal Science Advances ${ }^{4}$ I expect to see more of this "academic activism" in the next year and onwards.

\section{Academic and research libraries} are key stakeholders in the advocacy for OA. What recommendations do you have for libraries to further the development of OA? I believe that librarians are the most well-informed and enthusiastic OA stakeholders in the university environment. However, it feels like faculty do not hear their voice. Too often I have attended library-organized OA events and the audience has consisted solely of librarians and a small number of alreadyconvinced faculty. Somehow, librarians need to engage more directly with their academic faculty - to educate them on the advantages they are missing out on, and to inform them about the better publication options that are now available to them. Holding an event in the library building is probably not going to do it. When was the last time you saw a professor in the library? Librarians need to expand their partnerships with faculty; they need to present in person at faculty meetings; they need to organize events at departmental locations and in collaboration with respected faculty members; and they need to have the proactive support and understanding of the dean of every school on campus. By building these relationships, I feel they will be in a much stronger position to help faculty transition to the OA future that is now almost upon us.

\section{Interview with Carly Strasser on open data and data management}

1. Please tell readers about yourself. I am a research data specialist and open science advocate at the California Digital Library, part of the University of California system. I have a $\mathrm{PhD}$ in Biological Oceanography, which informs my work on helping researchers better manage and share their data.

2. What do you think was the most significant development in open data in the past 12 month? In data management? The most significant development related to open data is probably the release of PLOS's new data availability policy and subsequent discussions. What was significant was that, for perhaps the first time, many researchers started to actively engage in this discussion. In the past, most of the conversations about data sharing have been among those of us who are passionate about it. This includes librarians, information professionals, service providers, etc. The \#PLOSfail drama was good evidence that we are finally starting to move this conversation into the academic mainstream: when publishers get involved, researchers start to pay attention. ${ }^{5}$

The most significant development for data management is actually ongoing. In response to the White House Office of Science and Technology Policy (OSTP) memo in February 2013 , federal agencies are beginning to release their responses and plans for ensuring their grantees are managing and sharing 
the data generated by their funded projects. Although the memo was over a year ago, only now are agency plans for compliance being made publicly available. Similar to the PLOS policy, I imagine that researchers will start to feel the effects of these changes in the near future and begin to pay attention to data stewardship issues. ${ }^{6}$

3. What issues in open data and data management do you think need immediate attention and action? We should all be working toward enabling the culture shift. That means reaching out to publishers to compel them to put data sharing policies in place, educating first-year graduate students about data management, reaching out to institutional stakeholders to partner in facilitating open data, and working toward understanding the unique needs of research communities that need help sharing their data. The culture shift will result from many small activities on the part of librarians, service providers, open science advocates, and others. We can all contribute.

4. What is your prediction of the development of open data and data management in the next 12 months? I think that we will see new open data solutions popping up in response to the OSTP memo, increasing funder mandates, and increasing involvement by institutions and libraries. It's an exciting time to be a part of this community, and the tools and services that can be used to facilitate good data stewardship are constantly evolving.

\section{Academic and research libraries are} key stakeholders in the advocacy for open data and data management. What recommendations do you have for the libraries to further the development of open data and data management? My biggest plea to librarians is to compel their library administration to shift focus away from outdated library tasks and toward data management. This means librarians need to have time to learn about these topics, understand how best to help researchers, and generally jump into data stewardship with both feet. Too often I think that libraries as an organization are overwhelmed by the increasing demands on time, decreasing staff, and decreasing budget. But data stewardship should be seen as an exciting opportunity, rather than yet another burden. Librarians are information professionals and well-positioned in institutions to be leaders in this field; they only have to embrace this role.

\section{Interview with Nicole Allen on open educational resources}

1. Please tell readers about yourself. I have been an advocate for open education and college affordability ever since I graduated college. I spent most of that time with the Student PIRGs directing a national grassroots campaign to reduce the cost of textbooks. ${ }^{7}$ Recently I joined SPARC to head up a new program focused on open education. I am a true believer that education is the key to advancing our future, and that openness is the paradigm for getting there.

2. What do you think was the most significant development(s) in the landscape of Open Educational Resources (OER) in the past 12 months? In my view, it is the burgeoning interest of the academic library community. Librarians are uniquely poised to help overcome many of the barriers that have held back the use of OER on campus, such as discoverability, quality assessment, and support for faculty. Although libraries have not been deeply engaged in the past, we are now seeing them step up as leaders by the dozen. Numerous libraries have launched programs with faculty to replace expensive textbooks with OER and library materials, using a model pioneered by Temple University. ${ }^{8}$ Perhaps the most successful example is UMass Amherst Libraries', which estimates it has saved students more than $\$ 1$ million to date. 9 Some libraries are also moving into the OER publishing space, both for open textbooks and other open courseware materials. The library community has had a transformative impact on scholarly communication by advancing OA, and I firmly believe they will do the same with OER.

3. What issue(s) about OER do you think warrants immediate attention and action? One of the largest challenges is making it easy to identify appropriate, high-quality 
OER. The quantity of free, open online content has grown exponentially, which makes it difficult to narrow it down to exactly the material a professor or student wants. One project that has done an excellent job at this is the University of Minnesota's Open Textbook Library. ${ }^{10}$ It is a catalog of openly licensed textbooks that have been pre-vetted for basic quality standards and then reviewed by faculty using a special rubric. I would like to see more institutions contribute reviews to that project and perhaps establish complimentary resources that focus on other types of open content.

4. What is your prediction of the development of OER in the next 12 months? Over the next 12 months there will be a flood of OER coming out into the marketplace. The largest wave will come from the first round of the Department of Labor's $\$ 2$ billion workforce training grant program, which requires all participating grantees to release educational materials under a Creative Commons Attribution license. ${ }^{11}$ We are also going to see a number of high-impact open textbooks from publishing projects at Rice University, Oregon State University, and SUNY. I think this influx of content will drive conversations about how to better organize and share content. My hope is that it will also help people see the potential of OER beyond just cutting costs, as a new infrastructure that can support innovative teaching and learning practices that are only possible in an open environment.

\footnotetext{
5. Some academic and research libraries have become key stakeholders in the advocacy for OER. What recommendations do you have for libraries to further the development of OER? The most important thing every library can do is incorporate OER into the interactions they have with faculty members. Every professor knows that the cost of textbooks is an issue for students, and many are actively seeking solutions. Start by providing information about what OER is and pointing out relevant examples. The University of Minnesota's list of open textbooks is a good place to start. Not all professors are ready to talk about creating OER, but some might be interested in ways to openly license and share
}

materials they have already created. A good time to raise awareness of OER is during International Open Education Week, which will take place March 9-13, 2015. ${ }^{12}$ Other information and programming to support libraries and OER is available through the SPARC website. ${ }^{13}$

\section{Notes}

1. David W. Lewis, "The Inevitability of Open Access: Update One," http://hdl. handle.net/1805/3471

2. John Bohannon, "Who's Afraid of Peer Review?" Science, 342, 60-65, http://dx.doi. org/10.1126/science.342.6154.60

3. Fair Access to Science and Technology Research Act of 2013, https://beta.congress. gov/bill/113th-congress/house-bill/708.

RCUK Policy on Open Access and Supporting Guidance, www.rcuk.ac.uk/RCUK - prod/assets/documents/documents /RCUKOpenAccessPolicy.pdf.

4. "Open Letter to The American Association for the Advancement of Science," https:// thewinnower.com/papers/open-letter-to-the -american-association-for-the-advancement -of-science.

5. "Lit Review: \#PLOSfail and Data Sharing Drama," http://datapub.cdlib.org/2014/03/13/ lit-review-plosfail-and-data-sharing-drama/.

6. "The New OSTP Policy \& What it Means," http://datapub.cdlib.org/2013/02/28/thenew-ostp-policy-what-it-means/.

7. Student PIRGs (Public Interest Research Groups), www.studentpirgs.org/.

8. The Alternate Textbook Project, http:// sites.temple.edu/alttextbook/.

9. The Open Education Initiative @ UMass Amherst, http://guides.library.umass.edu / content.php?pid=87648\&sid $=4778777$.

10. Open Textbook Library, http://open. umn.edu/opentextbooks/.

11. The Trade Adjustment Assistance Community College and Career Training (TAACCCT) Grant Program, www.doleta. gov/taaccet/.

12. Open Education Week, www. openeducationweek.org/.

13. Open Education, www.sparc.arl.org /issues/oer. $\boldsymbol{n}$ 